\title{
Original article (short paper) \\ Use of combined method, accelerometer and international physical activity questionnaire, to determinate occurence of physical inactivity in adults
}

\author{
Rodrigo Pereira da Silva \\ Universidade Metropolitana de Santos, Santos, SP, Brazil \\ Evandro Forneas Sperandio \\ Universidade Federal de São Paulo, Santos, SP, Brazil \\ Agatha Caveda Matheus \\ Vinicius Tonon Lauria \\ Faculdade Praia Grande, Praia Grande, SP, Brazil \\ Flavio Rossi de Almeida \\ Vitor Rossi de Almeida \\ Universidade Federal de São Paulo, Santos, SP, Brazil \\ Antonio Ricardo Gagliardi \\ Rodolfo Leite Arantes \\ Marcelo Romiti \\ Angiocorpore, Medicina Cardiovascular, Santos, SP, Brazil \\ Victor Zuniga Dourado \\ Universidade Federal de São Paulo, Santos, SP, Brazil
}

\begin{abstract}
Aim: Evaluate and compare the proportion of Physical inactivity (PI) and associated factors by IPAQ questionnaire, triaxial accelerometry and the combination of both. Adults aged 18 years were enrolled $(\mathrm{n}=250)$. Methods: We considered PI as $<600 \mathrm{MET}-\mathrm{min} /$ wk in the IPAQ total score, $<150 \mathrm{~min} / \mathrm{wk}$ of moderate-to-vigorous physical activity in 7 days accelerometry, and the combination of both criteria. Clinical assessment, spirometry, cardiopulmonary exercise test, bioelectrical impedance, isokinetic dynamometry, postural balance, and six-minute walk test were also performed. For participants practicing aquatic, martial arts or cycling, only the IPAQ criterion was considered. Results: Proportions of PI were significantly different among methods (IPAQ, 10\%; accelerometry, 20\%; combination, 25\%). After multivariate logistic regressions, PI was determined by age, sex, educational level, risk factors for cardiovascular disease, lean body mass, cardiorespiratory fitness, and postural balance. Conclusion: Thus, the combined method for determining PI and associated factors in adults showed great validity, indicating that questionnaires and accelerometers are complementary and should be utilized in combination in epidemiological studies.
\end{abstract}

Keywords: sedentary lifestyle; energy metabolism; physical fitness.

\section{Introduction}

Physical inactivity (PI) is a major risk factor for many diseases, particularly cardiovascular diseases ${ }^{1,2}$. Currently, about $14 \%$ of the Brazilian adult population does not practice any physical activity, in the work environment, in transportation, in domestic work or in their leisure time ${ }^{3}$. Insufficiently active individuals are those who perform physical activities, but in quantity and intensity not enough to be classified as active as they do not meet the recommendations of at least 150 minutes/week of moderate-to-vigorous physical activity in daily life (PADL) $)^{1,2}$.

The simplest way to assess the PADL is using questionnaires. This tool has been widely used in population-based samples due to its low cost and its ability to collect detailed information on the type of activity ${ }^{4}$. Among these questionnaires, the most widely used are the International Physical Activity Questionnaire (IPAQ $)^{5}$. However, the self-report may generate biases of interpretation and accuracy of the information provided, particularly in individuals with lower educational level $\mathrm{e}^{6,7}$. Accordingly, to address the main limitations of questionnaires, the PADL has been assessed in the last few years through motion sensors. Among then, triaxial accelerometers are the most accurate and reliable method compared to the doubly labeled water and has been recommended for routine strategy in epidemiological studies ${ }^{8}$.

Recent studies have shown conflicting results between the IPAQ and accelerometers ${ }^{6,9,10}$. The questionnaire may 
overestimate $^{7}$ the PADL compared to accelerometers. However, motion sensors are not able to measure water activities, martial arts, strength training, upper body activities and cycling, underestimating the PADL of the practitioners of these modalities ${ }^{11}$.

Although the assessment of the physical activity patterns and energy expenditure in epidemiological studies is essential, few studies have assessed the PADL combining the results of the instruments mentioned above ${ }^{12,13}$. Instead, one of these instruments is often chosen and, more recently, the accelerometer has been prioritized. It would be reasonable to state that the questionnaire could supplement the information obtained by accelerometry, maximizing the assessment of the PADL in adults. Using only the questionnaire, especially for individuals who routinely perform water activities like swimming, combat sports, and cycling, could also improve the assessment of PADL. There are limitations in these environments and are not adequately captured by accelerometers, and may underestimate measurement estimate ${ }^{14,15}$.

We hypothesized that the combination of the IPAQ questionnaire and triaxial accelerometer is the best strategy to assess the proportion of physically inactive adults. This combined method could be more valid, associating with several recognized important predictors of PI in the general population. Accordingly, we aimed to evaluate and compare the proportion of PI in adults assessed by the IPAQ questionnaire, triaxial accelerometer and the combination of both. Also, we investigated associated factors of PI assessed by the combined method proposed here.

\section{Methods}

We evaluated 251 participants with a mean of $44 \pm 15$ years, of which 150 were women and 101 men, with a weight of $74.7 \pm 17,4 \mathrm{~kg}$ and a height of $1.64 \pm 0.10$ in a cross-sectional design. Participants were selected from the EPIMOV Study (Epidemiological Study of Human Movement and Hypokinetic Diseases). Briefly, the EPIMOV Study is a cohort study with the main objective of investigating the longitudinal association between sedentary behavior (which is the term for activities that are performed in the lying or sitting position and do not increase energy expenditure above resting levels, $\leq 1.5$ metabolic equivalents (METs) ${ }^{16}$, and PI with the occurrence of hypokinetic diseases, especially cardiorespiratory diseases. All participants underwent a general health screening supervised by a physician. First, they answered the physical activity readiness questionnaire (PAR-Q) ${ }^{17}$. Second, we assessed self-reported cardiovascular risk factors. Participants were inquired about the familiar history of cardiovascular disease and the presence of hypertension, diabetes, dyslipidemia, smoking and $\mathrm{PI}^{18}$. We investigated smoking by self-report and smoking load was calculated in pack-years. Third, Body weight and height were measured, and body mass index (BMI) was calculated. Participants with (BMI) $\geq 30 \mathrm{~kg} /$ $\mathrm{m}^{2}$ were considered obese. The following demographic variables were analyzed: age, sex, race, place of residence and schooling. We included only participants free of cardiac, respiratory and locomotor diseases.
After selection, all participants signed an informed consent. The local Ethics Committee on Human Research approved the present study.

\section{Design}

The assessments proposed by the present study were carried out in two days, seven days apart. In the first visit, participants underwent general health screening, anthropometrics, spirometry and cardiopulmonary exercise test (CPET). At the end of the assessment, participants were informed how to use the triaxial accelerometer for the subsequent seven days. In the second visit, they returned the accelerometer, answered the IPAQ, then conducted an assessment of body composition by bioelectrical impedance, isometric and isokinetic muscle function and postural balance. At the end of the second visit, participants underwent the six-minute walk test (6MWT).

\section{Spirometry}

The forced vital capacity maneuver was carried out using a properly calibrated spirometer (Quark PFT, COSMED, Pavonadi Albano, Italy) according to the criteria established by the American Thoracic Society ${ }^{19}$. Forced expiratory volume in one second (FEV1), forced vital capacity (FVC) and the FEV1/FVC ratio were measured in absolute and predicted values ${ }^{20}$. The restrictive spirometric ${ }^{21}$ pattern was identified as previous described (i.e., FEV1/FVC $>0.70$ and $\mathrm{FVC}<80 \%$ of predicted $)^{12}$.

\section{Cardiopulmonary exercise test}

The CPET was performed on a treadmill (ATL, Inbrasport, Curitiba, Brazil) under a ramp protocol established according to the estimated maximum oxygen uptake $\left(\mathrm{V}^{\prime} \mathrm{O}_{2}\right)$ of each participant. Heart rate was monitored throughout the test by a 12-lead electrocardiogram (C12x, COSMED, Pavonadi Albano, Italy). Gas exchange and ventilatory variables were analyzed breath by breath, using periodically calibrated gas analyzer (Quark PFT, COSMED, Pavonadi Albano, Italy). The following criteria were used for determining the maximum effort: maximum heart rate (HR max) of at least $85 \%$ of predicted for age (220 - age) or rate of gas exchange $(\mathrm{R}) \geq 1.0$ or $\mathrm{V}^{\prime} \mathrm{O}_{2}$ plateau. Oxygen uptake, carbon dioxide production $\left(\mathrm{V}^{\prime} \mathrm{CO}_{2}\right)$; and minute ventilation $\left(\mathrm{V}^{\prime} \mathrm{E}\right)$ were obtained. The data were filtered every $15 \mathrm{~s}$ by arithmetic average, and the average of the $\mathrm{V}^{\prime} \mathrm{O}_{2}$ values in the last $15 \mathrm{~s}$ at peak incremental exercise was used as representative of peak $\mathrm{V}^{\prime} \mathrm{O}_{2}$. The anaerobic threshold (AT) was obtained by the v-slope method as previous described ${ }^{23}$.

\section{Body composition}

We measured body composition by bioelectrical impedance (310E, BIODYNAMICS, Detroit, USA) carried out at ambient 
temperature. Resistance and reactance were determined with the participant in the supine position as previous described ${ }^{(24)}$. We calculated lean body mass (LBM) and body fat using groupspecific equations for healthy individuals ${ }^{24}$.

\section{International Physical Activity Questionnaire}

The PADL was quantified using the long version of the IPAQ questionnaire validated for local culture and language ${ }^{25}$. Total energy expenditure in high, moderate and low-intensity physical activities as well as in labor, transportation, recreation and leisure physical activities were quantified in MET/min.week ${ }^{-1}$. We considered physically inactive those who performed less than $600 \mathrm{MET} / \mathrm{min}$. $^{-1} \mathrm{eek}^{-1}$ in the total score of the questionnaire ${ }^{26}$.

\section{Postural balance}

We evaluated postural balance by the measure of the center of pressure bipedal (COP) on a force platform (BIOMEC 400, EMGSystem, Brazil). The frequency of the data acquisition was set at $100 \mathrm{~Hz}$. Participants were instructed to remain as static as possible in the following situations: Bipedal support with open eyes; bipedal support with eyes closed; semi-tandem support with eyes open; and semi-tandem support with eyes closed. Each position was held for 30 seconds. In the case of situations with open eyes, participants were instructed to look at a target of 4.5 $\mathrm{cm}$ in diameter, positioned at the eye level.

\section{Peripheral muscle function}

We assessed muscle function on an isokinetic dynamometer (Biodex, Lumex, Inc., Ronkonkoma, NY). The gravity was properly corrected throughout all tests. Peak torque (PT) in Nm was assessed by two tests of five movements at $60 \%$ s. After a rest period of at least five minutes, participants underwent tests at $300 \%$ s to register the total work (TT), in kJ, after 30 repetitions. We considered the highest value for analysis in all the tests mentioned above. These tests were applied to the dominant lower and upper limbs. Participants were strongly encouraged during all the tasks.

\section{Six-minute walk test}

The 6MWT was performed according to the standards of the American Thoracic Society ${ }^{27}$. The distance traveled on the test (6MWD) was recorded in meters and in the percentage of predicted values ${ }^{28}$.

\section{Accelerometry}

We used triaxial accelerometers to assess PADL (ActiGraph, GTX 3, MTI, Pensacola, FL). The software used for analysis was actilife 6.11.9. The accelerometry was performed during seven consecutive days. We instructed all the participants on how the accelerometer should be positioned at the waist above the dominant hip. Participants completed a checklist to assess whether your day was representative. We considered only valid days with at least 12 hours of monitoring, starting at the moment of awakening. The time spent in each physical activity intensity and the energy expenditure were obtained and therefore the average of at least four valid days was calculated. The time of use was identified by asking the volunteer to remove the accelerometer from the hip region at the time of going to sleep, since we did not evaluate the sleep period in this study. We considered physically inactive those who did not perform at least $150 \mathrm{~min} /$ week of moderate-tovigorous physical activity. The valid data were the use of accelerometers at least four days, one being a weekend. The day was considered valid when they were recorded for at least 10 hours of recording. Data were collected at a frequency of 30 $\mathrm{Hz}$ and analyzed in epochs of $60 \mathrm{~s}$. For the calculation of the minutes spent in moderate and vigorous activities per week, the sum of all valid days was adjusted by the number of valid days and multiplied by seven, thus obtaining the individual weekly average. For the classification of physical activity in the different intensities, the cut-off point was the one proposed by Freedson et al.29, being considered as moderate activity counts between 1,952 and 5,724, and above 5,725 counts as vigorous activities.

\section{Combined method for assessing PADL}

We inquired participants about the realization of aquatic physical activities (e.g., swimming) and martial arts/body contact activities, upper body physical activities, and cycling. For those who met these criteria, we considered only the results of the IPAQ for identifying PI (i.e., $<600 \mathrm{MET} / \mathrm{min} \mathrm{week}^{-1}$ ). For these individuals were not using the accelerometer at the moments of the practices of the swimming pool (because it is not water resistant) and fights, and also by the limitations in the use of cycling ${ }^{30}$. Also, in the combined method proposed here, we considered physically inactive all participants who showed total score of the IPAQ $<600$ $\mathrm{MET} / \mathrm{min}$ week $^{-1}$ and/or quantity and intensity of PADL $<150$ $\mathrm{min} /$ week of moderate-to-vigorous physical activity obtained by triaxial accelerometry.

\section{Statistical analysis}

Statistical analyzes were performed with SPSS version 22.0. We performed a descriptive analysis including frequencies and histograms initially. Physical inactivity was investigated as a categorical variable. The associations between PI and the studied variables were evaluated by calculating the odds ratio and its 95\% confidence interval. Proportions were compared using the $\mathrm{x}^{2}$ test and continuous variables were compared by the Student $\mathrm{t}$ between physically active and inactive participants in each of the methods utilized (IPAQ, accelerometry, and combined method). 
The proportion of physically inactive participants was calculated and compared between the methods of evaluation. Also, the agreement between IPAQ and accelerometry was evaluated by Kappa test. The kappa values, equal to or greater than 0.80 , were considered adequate.

The numbers of variables and as co-variables in the logistic regression statistical models to $1 / 10$ were evaluated from the number of participants or at least ten observations for each variable included in the model. The variables of interest were included in the model the following groups: demographic, anthropometric, body composition, clinics, cardiorespiratory fitness, and postural balance.

Energy expenditure, the number of steps performed and the intensity of daily physical activity were evaluated descriptively and the average daily time spent standing, lying and sitting were evaluated as well.

We performed multivariate logistic regressions using PI as the outcome. The objective was to obtain the best model, discarding non-significant variables with almost no contribution to the setting. The processing was performing through simple logistic regression for each independent variable. In the case of categorical variables, the transformation was performed using dummy variables in the categories as a reference. The variables that presented $\mathrm{p}$ values $\leq 0.20$ were selected. The likelihood ratio test verified the overall fit of the model. Age and BMI were initially analyzed as continuous variables and in the case of lack of significance they were transformed into categorical variables. Age was stratified into 20-39, 40-59 and $\geq 60$ years and BMI in 18 to $24.9,30$ to 34.9 and $25-29.9$, and $\geq 35 \mathrm{~kg} / \mathrm{m}^{2}$, respectively representative of young adults, middle-aged and older adults and normal weighted, overweighed and obese participants. Three regression models were constructed using PI as the outcome obtained by the combined method. Values of odds ratio and its $95 \%$ confidence limits were calculated. One of the goals was to quantify the number of significant predictors in each of the PI identification methods. The probability of an alpha error was set at $5 \%$.

\section{Results}

There was evenly distributed mean values of BMI were representative of overweight (Table 1). Spirometric indices showed that participants were free of lung obstruction. Twenty-five participants $(10 \%)$ presented restrictive spirometric pattern. Participants were predominantly white. Considering the cardiovascular risk assessment, almost half of our participants had a moderate cardiovascular risk with two or more cardiovascular risk factors.

Table 1. General characteristics of the 251 participants

\begin{tabular}{lcc}
\hline & Mean \pm SD & Count (\%) \\
\hline Age (years) & $44 \pm 15$ & \\
\hline Age groups & & \\
\hline $20-29$ years & & $56(22)$ \\
\hline
\end{tabular}

\begin{tabular}{lll}
\hline $30-39$ years & $43(17)$ \\
$40-49$ years & $54(22)$ \\
$50-59$ years & $58(23)$ \\
$\geq 60$ years & Sex & $40(16)$ \\
\hline & & $150(60)$ \\
\hline Females & & $101(40)$ \\
Males & & \\
Weight $(\mathrm{kg})$ & $74.7 \pm 17.4$ & \\
Height $(\mathrm{cm})$ & $1.64 \pm 0.10$ & \\
Body mass index $\left(\mathrm{kg} / \mathrm{m}^{2}\right)$ & $27 \pm 5$ & \\
\hline
\end{tabular}

\begin{tabular}{|c|c|c|}
\hline \multicolumn{3}{|c|}{ Body mass index classification $\left(\mathrm{kg} / \mathrm{m}^{2}\right)$} \\
\hline Normal weight (18.5-24.9) & & $107(43)$ \\
\hline Overweight (25.0-29.9) & & $69(27)$ \\
\hline Obesity class 1 (30.0-34.9) & & $51(20)$ \\
\hline Obesity classes 2 and $3(\geq 35.0)$ & & $24(10)$ \\
\hline Fat body mass (\%) & $29 \pm 9$ & \\
\hline Lean body mass (kg) & $52 \pm 11$ & \\
\hline $\mathrm{FVC}(\mathrm{L})$ & $3.72 \pm 1.03$ & \\
\hline FVC (\% pred.) & $96 \pm 14$ & \\
\hline $\mathrm{FEV}_{1}(\mathrm{~L})$ & $3.04 \pm 0.82$ & \\
\hline $\mathrm{FEV}_{1}(\%$ pred. $)$ & $95 \pm 14$ & \\
\hline $\mathrm{FEV}_{1} / \mathrm{FVC}(\%)$ & $82 \pm 6$ & \\
\hline \multicolumn{3}{|c|}{ Educational level } \\
\hline Under graduated & & $159(64)$ \\
\hline Graduated & & $92(36)$ \\
\hline $\begin{array}{l}\text { Familiar history of cardiovascular } \\
\text { disease }\end{array}$ & & $64(25)$ \\
\hline Arterial hypertension & & $26(10)$ \\
\hline Diabetes & & $20(8)$ \\
\hline Dyslipidemia & & $68(27)$ \\
\hline Smoking & & $28(11)$ \\
\hline
\end{tabular}

$\mathrm{FVC}=$ forced vital capacity; FEV1 = forced expiratory volume in the $1 \mathrm{~s}$.

According to the IPAQ results, $89 \%$ of participants had a median-to-high level of physical activity (Table 2 ), that is, the volunteers performed between more than $600 \mathrm{METs} / \mathrm{min} /$ week to less than $3000 \mathrm{METs} / \mathrm{min} /$ week. Participants reported 240-285 minutes spent sitting. About $10 \%$ of the participants reported practicing aquatic physical activities and martial arts/body contact, upper body and cycling activities (Table 2).

The proportion of PI was significantly different among the methods utilized (Figure 1). There was poor agreement between IPAQ and accelerometry $($ Kappa $=0.152 ; \mathrm{p}=0.01)$. 
Table 2. Level of physical activity in daily life assessed by the International Physical Activity Questionnaire (IPAQ) and triaxial accelerometer

\begin{tabular}{cc}
\hline IPAQ & Median (interquartile range) or count (\%) \\
\hline Work (MET-min/week) & $0(0-495)$ \\
Transportation (MET-min/week) & $264(33-707)$ \\
Domestic activities (MET-min/week) & $420(0-1440)$ \\
Leisure (MET-min/week) & $495(0-1916)$ \\
Total score (MET-min/week) & $2654(1539-5238)$ \\
Time spent sitting per day during weekdays (min) & $285(120-465)$ \\
Time spent sitting per day during the weekend (min) & $240(120-360)$ \\
\hline
\end{tabular}

\begin{tabular}{|c|c|}
\hline \multicolumn{2}{|c|}{ Classification of physical activity level } \\
\hline Low $(\leq 600 \mathrm{MET}-\mathrm{min} /$ week $)$ & $26(10)$ \\
\hline Median (600 - 3000 MET- min/ week) & $109(43)$ \\
\hline High ( $\geq 3000$ MET-min/week) & $116(46)$ \\
\hline \multicolumn{2}{|c|}{ Accelerometry (7 days) } \\
\hline Kcal/day & $350(240-532)$ \\
\hline Sedentary physical activity (\%) & $76(71-82)$ \\
\hline Light physical activity (\%) & $13(10-17)$ \\
\hline Lifestyle physical activity (\%) & $6(4-7)$ \\
\hline Moderate to very vigorous physical activity (\%) & $4(3-6)$ \\
\hline Time spent sitting (hours/wk)* & $44(36-52)$ \\
\hline Time spent sitting (\%) & $25(20-30)$ \\
\hline Aquatic, contact and cycling activities & $22(9)$ \\
\hline Average steps per day & $7401(5781-9641)$ \\
\hline
\end{tabular}

$* \mathrm{p}<0.05$ : accelerometry vs. IPAQ

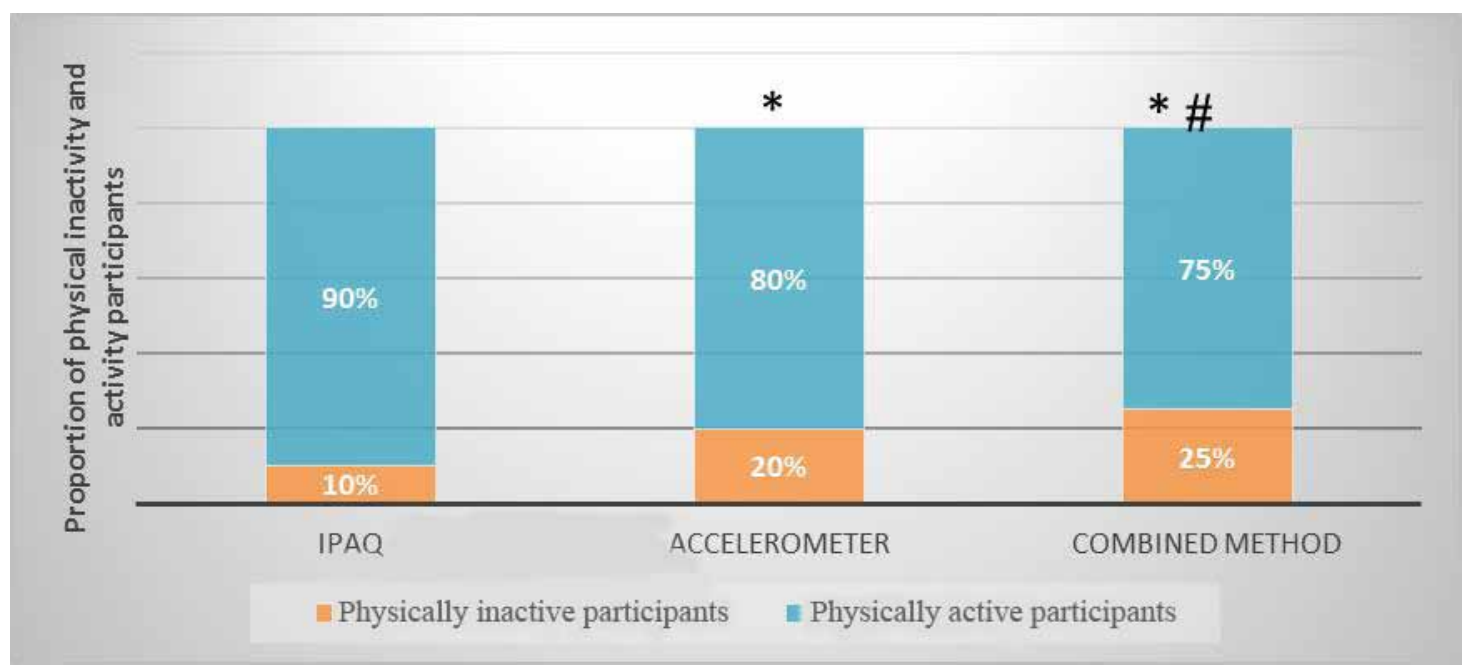

Figure 1. The proportion of physically inactivity and activity participants according to the evaluation method: International Physical Activity Questionnaire (IPAQ), seven days triaxial accelerometry and the combination of both. ${ }^{*} \mathrm{p}<0,05$ vs. IPAQ; $\neq \mathrm{p}<0,05$ vs. Accelerometry 
Tables 3 and 4 show the main variables associated with PI according to the combined method. Demographic factors such as age and education level were significantly different between physically active and inactive participants (Table 3 ).

Table 3. Demographics. anthropometrics and cardiovascular risk factors in the studied sample according to the method utilized for assessing physical activity in daily life.

\begin{tabular}{|c|c|c|}
\hline & \multicolumn{2}{|c|}{ Physical inactivity } \\
\hline & \multicolumn{2}{|c|}{ Combined method } \\
\hline & No & Yes \\
\hline Age (yr) & $40 \pm 14$ & $56 \pm 10^{*}$ \\
\hline \multicolumn{3}{|l|}{ Sex } \\
\hline Females & $115.0(60.8)$ & $35.0(56.5)$ \\
\hline Males & $74.0(39.2)$ & $27.0(43.5)$ \\
\hline \multicolumn{3}{|l|}{ Educational level } \\
\hline Under graduated & $75(39.6)$ & $37(59.7)^{*}$ \\
\hline Graduated & $114(60.4)$ & $25.0(40.3)^{*}$ \\
\hline Weight (kg) & $76.2 \pm 18.6$ & $70.0 \pm 12.2^{*}$ \\
\hline Height (m) & $1.65 \pm 0.10$ & $1.62 \pm 0.10$ \\
\hline BMI $\left(\mathrm{kg} / \mathrm{m}^{2}\right)$ & $27.8 \pm 5.9$ & $26.4 \pm 2.9$ \\
\hline Waist circumference $(\mathrm{cm})$ & $87.0 \pm 16.0$ & $87.0 \pm 11.0$ \\
\hline Waist to hip ratio & $0.84 \pm 0.09$ & $0.88 \pm 0.09^{*}$ \\
\hline Familiar history of CVD & $149.0(78.8)$ & $40.0(21.2)^{*}$ \\
\hline Arterial hypertension & $177.0(93.7)$ & $12.0(6.3)^{*}$ \\
\hline Diabetes & $179.0(94.7)$ & $10.0(5.3)^{*}$ \\
\hline Dyslipidemia & $157.00(83.1)$ & $32.0(16.9)^{*}$ \\
\hline Obesity & $126.0(66.7)$ & $63.0(33.3)^{*}$ \\
\hline Current smoking & $176.0(93.1)$ & $13.0(6.9)^{*}$ \\
\hline
\end{tabular}

Data presented as mean \pm SD (continuous variables) and as count $(\%)$ for categorical variables. IPAQ $=$ International Physical Activity Questionnaire; IMC $=$ body mass index; ${ }^{*} \mathrm{p}<0.05$ : physically active vs. physically inactive participants

Considering cardiovascular risk factors, we found that familiar history of cardiovascular disease, dyslipidemia, and current smoking, were significantly different between physically active and inactive participants. PI showed significant association with some of the risk factors for cardiovascular disease (Table 3). The low level of physical fitness was significantly associated with PI
(Table 4). Among the physical fitness variables, peak $\mathrm{V}^{\prime} \mathrm{O}_{2}, \mathrm{AT}$, maximum $\mathrm{HR}$, maximum $\mathrm{V}^{\prime} \mathrm{O}_{2} / \mathrm{HR}$, maximum $\mathrm{V}^{\prime} \mathrm{E}$ and isokinetic muscle strength of the knee were significantly lower in the physically inactive participants. Postural balance, lean body mass, and 6MWD were significantly lower in physically inactive participants in only one or two proposed methods of evaluation (Table 4).

Table 4. Physical fitness variables in the studied sample according to the evaluation method utilized for assessing physical activity in daily life.

\begin{tabular}{llc}
\hline & \multicolumn{2}{c}{ Physical inactivity } \\
\cline { 2 - 3 } & \multicolumn{2}{c}{ Combined method } \\
\cline { 2 - 3 } & & Yes \\
\hline Cardiopulmonary exercise testing & & $1781.9 \pm 624.8^{*}$ \\
\hline
\end{tabular}




\begin{tabular}{lll}
\hline Peak $\mathrm{VO}_{2}(\mathrm{ml} / \mathrm{min} / \mathrm{kg})$ & $32.3 \pm 11.0$ & $25.0 \pm 7.3^{*}$ \\
Anaerobic threshold $(\mathrm{ml} / \mathrm{min})$ & $1681.9 \pm 706.3$ & $1192.8 \pm 423.8^{*}$ \\
Maximum heart rate $(\mathrm{bpm})$ & $168.6 \pm 17.8$ & $152.8 \pm 20.0^{*}$ \\
Maximum pulse $\mathrm{O}_{2}(\mathrm{ml} / \mathrm{min} / \mathrm{bpm})$ & $14.4 \pm 5.2$ & $11.5 \pm 3.4$ \\
\hline Body composition & & $68.0 \pm 11.2$ \\
\hline Lean body mass $(\%$ of total $)$ & $67.3 \pm 18.4$ & $30.6 \pm 6.6$ \\
Fat body mass $(\%$ do total) & $28.8 \pm 9.1$ & $113.1 \pm 50.8^{*}$ \\
\hline Peripheral muscle function & & $30.7 \pm 14.0$ \\
\hline Peak torque & & $1266.6 \pm 583.9 *$ \\
Knee extension peak torque at $60 \% \mathrm{~s}(\mathrm{Nm})$ & $34.5 \pm 22.1$ & $629.9 \pm 276.9$ \\
Elbow flexion peak torque at $60 \% \mathrm{~s}(\mathrm{Nm})$ & & \\
Total work & $1640.7 \pm 708.7$ & $778.3 \pm 545.9$ \\
Knee extension total work at $300 \% \mathrm{~s}(\mathrm{~kJ})$ & & \\
Elbow flexion total work at $300 \% \mathrm{~s}(\mathrm{~kJ})$ & & \\
\hline
\end{tabular}

$* \mathrm{p}<0.05$ : physically active vs. inactive.

After multivariate logistic regression analyses, the main predictors of PI determined by combined method were age, female sex, lean body mass, familiar history of cardiovascular disease, dyslipidemia, obesity, smoking, peak $\mathrm{V}^{\prime} \mathrm{O}_{2}$ and COP (Table 5).

Table 5. Results of the multivariate logistic regressions for assessing predictors of physical inactivity $(\mathrm{n}=251)$

\begin{tabular}{|c|c|c|c|}
\hline \multirow{4}{*}{ Predictors } & \multicolumn{3}{|c|}{ Physical inactivity } \\
\hline & \multicolumn{3}{|c|}{ Combined method } \\
\hline & \multicolumn{3}{|c|}{$95 \%$ confidence interval } \\
\hline & Odds ratio & Lower limit & Upper limit \\
\hline Age (yr) & $1.104 *$ & 1.024 & 1.190 \\
\hline Sex & $9.935^{*}$ & 4.511 & 18.578 \\
\hline Education level (graduated) & 0.688 & 0.467 & 1.013 \\
\hline Fat body mass ( $\%$ of total $)$ & 0.911 & 0.780 & 1.064 \\
\hline Familiar history of CVD & $8.230^{*}$ & 1.985 & 34.117 \\
\hline Arterial hypertension & $7.438 \neq$ & 0.888 & 62.283 \\
\hline Diabetes & 1.162 & 0.161 & 8.367 \\
\hline Dyslipidemia & $12.740 *$ & 2.874 & 56.465 \\
\hline Obesity & $1.982 *$ & 1.845 & 1.998 \\
\hline Smoking & $10.739 *$ & 1.656 & 69.641 \\
\hline Peak V'O ${ }_{2}(\mathrm{ml} / \mathrm{min} / \mathrm{kg})$ & $0.837 *$ & 0.739 & 0.948 \\
\hline COP bipedal $\left(\mathrm{cm}^{2}\right)$ & $1.343^{*}$ & 1.013 & 1.780 \\
\hline PT of knee extension at $60^{\circ} / \mathrm{s}(\mathrm{Nm})$ & 1.015 & 0.992 & 1.039 \\
\hline TW knee extension at $300 \%$ s $(\mathrm{kj})$ & 0.999 & 0.997 & 1.001 \\
\hline 6MWD (m) & 1.005 & 0.995 & 1.016 \\
\hline
\end{tabular}

V'O2 = oxygen uptake; $\mathrm{COP}=$ center of pressure; $\mathrm{PT}=$ peak torque; $\mathrm{TW}=$ total work; $6 \mathrm{MWD}=$ six- minute walk; distance; *p $<0.05$ : significance for odds ratio 


\section{Discussion}

We assessed the proportion of PI among asymptomatic adults using the IPAQ and triaxial accelerometers. The IPAQ significantly underestimated the proportion of physically inactive individuals. However, in spite of the scarce studies showing the efficacy agreement between IPAQ and accelerometry, we suggest the combination of the two methods may be more valid and provided significantly higher prevalence of physical inactivity.

The main finding of the present study was that the combination of questionnaire and triaxial accelerometry resulted in the significantly higher proportion of PI compared to IPAQ and accelerometry separately. We also observed after multivariate logistic regressions that PI assessed by the combined method proposed in the present study was significantly associated with a larger number of relevant attributes.

Previous findings in the literature are very conflicting. This fact can primarily be attributed to the complexity of evaluation of PADL. Select the most suitable tool is challenging, especially in the general population. Moreover, the various dimensions of physical activity require different assessment tools ${ }^{31}$.

Several studies have compared accelerometers with questionnaires for assessing PADL ${ }^{32-34}$. However, few have proposed to assess the combination of the two methods ${ }^{32}$. Since the gold standard for evaluating PADL is not determined yet in large-scale epidemiological studies, questionnaires and accelerometers have been the instruments most commonly used ${ }^{8}$. Accelerometers provide information about the frequency, duration, intensity and pattern of physical activity and are capable of storing information for a long period. Unfortunately, they underestimate the energy expenditure of some activities of daily life and are unable to accurately assess physical activities with arms, water activities, cycling and walking in a steep climb, among others. Questionnaires, in turn, represent the most frequently used method in epidemiological studies focusing mainly on its advantage of low cost. It also presents as one of its main strengths the ability to discern some dimensions of daily physical activity, such as occupational activities, transport and leisure time. Although the questionnaires are accurate to assess physical activity of moderate-to-vigorous physical activity, they present difficulties in quantifying low-intensity physical activities, especially in some specific groups (e.g., older adults and women). Therefore, it is reasonable to assert that the combination of questionnaire and accelerometers may be the best strategy for more accurate assessment of $\mathrm{PADL}^{8}$.

The proportion of PI observed in the combined method proposed here was $25 \%$. Our results are in agreement with literature. In a large study involving 212,021 participants from 51 countries, the average prevalence of PI were $18 \%, 15 \%$ for men and $20 \%$ for women, with wide variation between 2 and $72 \%{ }^{35}$. In every country involved, women and older adults were more likely to be physically inactive ${ }^{35}$. Brazil was involved in this study ${ }^{35}$ including 4,458 individuals. The results showed $26 \%$ of PI, very similar to the $25 \%$ found in the present study combining the two instruments. Several Brazilian studies have investigated the prevalence of PI, mostly using questionnaires. However, as the present study, the vast majority was held involving only one city. Unfortunately, multicenter studies are scarce and surely involve few cities. These national data using the short version of the IPAQ indicate a prevalence of PI between 29 and $31 \%{ }^{36}$. We found in the present study lower prevalence through the long version of the IPAQ $(10 \%)$. This fact can be attributed primarily to the different questionnaires used and the feature conducive to physical activity in the city in which the present study was conducted (Santos, São Paulo, Brazil). This city is mostly flat, coastal and located in the southeast region. In fact, Brazilian multicenter studies showed that the prevalence of PI is lower in the South and Southeast regions (about 24\%) ) $^{37,38}$. We were unable to find Brazilian studies that assessed the prevalence of PI among adults through triaxial accelerometry.

Our study showed inconsistent agreement between accelerometry and IPAQ (Kappa $=0.152 ; p=0.01)$. This finding is in agreement with previous studies. Chastin et al. ${ }^{39}$ observed a weak correlation between accelerometry and IPAQ. The agreement between then was also weak considering the wide confidence interval ${ }^{39}$. Oyeyemi et al. ${ }^{40}$ evaluated 144 participants underwent triaxial accelerometry and IPAQ. The correlation between the times in moderate-to-vigorous physical activity obtained by the two instruments was moderate, and the limit of agreement was wide. Again, the questionnaire underestimated the amount of sedentary physical activity ${ }^{40}$. Men and women reported time spent in sedentary physical activity, on average, $131 \mathrm{~min} /$ day less than the amount obtained by accelerometry and the correlation between the two methods was weak ${ }^{41}$. The IPAQ presented limitations to classify adults in low ranges and high intensity of physical activity, with the difference increasing progressively with the increasing amount and intensity of physical activity ${ }^{42,43}$.

Our results showed greater validity when we combine the two methods of assessing PADL. Harris et al. ${ }^{44}$ observed differences in concurrent validity when compared a specific physical activity questionnaire and triaxial accelerometry. The results of accelerometry were correlated consistently with general health, anthropometric and psychological variables while the questionnaire was associated only with the psychological variables. Sabia et al ${ }^{45}$ observed stronger correlations between the results of accelerometry and anthropometric and body composition variables compared to the physical activity questionnaire. The results mentioned above suggest that the validity of the accelerometer is more consistent compared to questionnaires. Our results suggest that the combination of these two methods might be even better. For reliability when using the two instruments is greater for subjects practicing aquatic activities, cycling, fights (accelerometry is not reliable), and individuals with little schooling and the elderly (overestimate the PADL).

After multivariate logistic regressions, we found a great number of significant predictors using the combined method, especially considering physical fitness variables (e.g., peak $\mathrm{V}^{\prime} \mathrm{O} 2$ and $\mathrm{COP}$ ). This fact may be attributed first to the overestimation of the quantity of PADL and lower precision for low-intensity related to questionnaires. On the other hand, the triaxial accelerometry may result in spurious interpretations of PADL regarding water, upper body, and cycling activities, etc.

The present study has limitations that should be considered. We recruited a convenience sample, which may introduce bias, 
for example, a higher proportion of women and higher education level. However, our results showed a proportion of PI as well as other demographic and anthropometric characteristics very compatible with the previously described in the literature for our metropolitan area. Moreover, the sample was statistically sufficient, especially for the construction of multivariate logistic regression models. To be used as a criterion of comparison and such as the cut-point utilized for moderate-vigorous physical activity.

We may conclude that the combined method proposed here resulted in the more reliable proportion of PI and was valid, being predicted by several demographic, clinical and physiological variables. Our findings have practical implications. They suggest that the main PADL assessment methods commonly used in epidemiological studies are complementary and should always be used in combination as a routine strategy.

\section{References}

1. Chodzko-Zajko WJ, Proctor DN, Fiatarone Singh MA, Minson CT, Nigg CR, Salem GJ, et al. American College of Sports Medicine position stand. Exercise and physical activity for older adults. Med Sci Sports Exerc. 2009;41(7):1510-30.

2. American College of Sports Medicine position stand. Progression models in resistance training for healthy adults. Med Sci Sports Exerc. 2009;41(3):687-708.

3. Ministério da Saúde. Vigilância de fatores de risco e proteção para doenças crônicas por inquérito telefônico. In: Saúde SdVe, editor. Brasília, 2012.

4. Ainsworth BE, Caspersen CJ, Matthews CE, Masse LC, Baranowski T, Zhu W. Recommendations to improve the accuracy of estimates of physical activity derived from self report. J Phys Act Health. 2012;9 Suppl 1:S76-84.

5. Barros MVG, Nahas MV. Reprodutibilidade (teste-reteste) do Questionário Internacional de Atividades Físicas (QIAF-Versão 6): um estudo-piloto com adultos no Brasil. Rev Bras Ciênc Mov. 2000;18(2):23-6.

6. Dyrstad SM, Hansen BH, Holme IM, Anderssen SA. Comparison of self-reported versus accelerometer-measured physical activity. Medicine and science in sports and exercise. 2014;46(1):99-106.

7. Garcia LMT, Barros MVG, Silva KS, Del Duca GF, Costa FFd, Oliveira ESA, et al. Socio-demographic factors associated with three sedentary behaviors in Brazilian workers. Cadernos de Saúde Pública. 2015;31(5):1015-24.

8. Lee I-M, Blair S, MaNSON J, Paffenbaerger Jr. RS. Epidemiologic methods in physical activity studies. Lee I-M, editor. New York: Oxford University Press; 2009. 328 p.

9. Fuentes Bravo M, Zuniga Paredes F, Rodriguez-Rodriguez FJ, Cristi-Montero C. [Occupational physical activity and body composition in adult women; pilot study]. Nutricion hospitalaria. 2013;28(4):1060-4.

10. Umstattd Meyer MR, Baller SL, Mitchell SM, Trost SG. Comparison of 3 accelerometer data reduction approaches, step counts, and 2 self-report measures for estimating physical activity in free-living adults. J Phys Act Health. 2013;10(7):1068-74.
11. Medina C, Barquera S, Janssen I. Validity and reliability of the International Physical Activity Questionnaire among adults in Mexico. Rev Panam Salud Publica. 2013;34(1):21-8.

12. Duncan MJ, Arbour-Nicitopoulos K, Subramanieapillai M, Remington G, Faulkner G. Revisiting the International Physical Activity Questionnaire (IPAQ): Assessing physical activity among individuals with schizophrenia. Schizophrenia research. 2016.

13. Wanner M, Probst-Hensch N, Kriemler S, Meier F, Autenrieth C, Martin BW. Validation of the long international physical activity questionnaire: Influence of age and language region. Preventive medicine reports. 2016;3:250-6.

14. Strath SJ, Kaminsky LA, Ainsworth BE, Ekelund U, Freedson PS, Gary RA, et al. Guide to the assessment of physical activity: Clinical and research applications: a scientific statement from the American Heart Association. Circulation. 2013;128(20):2259-79.

15. Pedisic Z, Bauman A. Accelerometer-based measures in physical activity surveillance: current practices and issues. British journal of sports medicine. 2015;49(4):219-23.

16. Owen N, Healy GN, Matthews CE, Dunstan DW. Too much sitting: the population health science of sedentary behavior. Exercise and sport sciences reviews. 2010;38(3):105-13.

17. Standardization of Spirometry, 1994 Update. American Thoracic Society. Am J Respir Crit Care Med. 1995;152(3):1107-36.

18. American College of Sports Medicine. ACSM's guidelines of exercise testing and prescription. 8th ed. Philadelphia: Lippincott Wiliams \& Wilkins; 2009. 265 p.

19. Miller MR, Hankinson J, Brusasco V, Burgos F, Casaburi R, Coates A, et al. Standardisation of spirometry. Eur Respir J. 2005;26(2):319-38.

20. Pereira CA, Sato T, Rodrigues SC. New reference values for forced spirometry in white adults in Brazil. J Bras Pneumol. 2007;33(4):397-406.

21. Pellegrino R, Viegi G, Brusasco V, Crapo R, Burgos F, Casaburi Rea, et al. Interpretative strategies for lung function tests. European Respiratory Journal. 2005;26(5):948-68.

22. Pereira C, Neder J. Diretrizes para testes de função pulmonar. J Bras Pneumol. 2002;28(Sup1 3):s1-s238.

23. Wasserman K, Hansen J, Sue DY, Whipp BJ, Casaburi R. Principles of exercise testing and interpretation. 4th ed. Philadelphia: Lippincott Wiliams \& Wilkins; 2005. 576 p.

24. Kyle UG, Genton L, Karsegard L, Slosman DO, Pichard C. Single prediction equation for bioelectrical impedance analysis in adults aged 20--94 years. Nutrition. 2001;17(3):248-53.

25. Matsudo S, Araújo T, Marsudo V, Andrade D, Andrade E, Braggion G. Questinário internacional de atividade f1 sica (IPAQ): estudo de validade e reprodutibilidade no Brasil. Rev bras ativ fís saúde. 2001;6(2):05-18.

26. Hallal PC, Gomez LF, Parra DC, Lobelo F, Mosquera J, Florindo AA, et al. Lições aprendidas depois de 10 anos de uso do IPAQ no Brasil e Colômbia. Journal of Physical Activity and Health. 2010;7((suppl 2)):S259-S64.

27. Laboratories ACoPSfCPF. ATS statement: guidelines for the sixminute walk test. American journal of respiratory and critical care medicine. 2002;166(1):111.

28. Dourado VZ, Vidotto MC, Guerra RLF. Reference equations for the performance of healthy adults on field walking tests. Jornal Brasileiro de Pneumologia. 2011;37(5):607-14. 
29. Freedson PS, Melanson E, Sirard J. Calibration of the Computer Science and Applications, Inc. accelerometer. Med Sci Sports Exerc. 1998;30(5):777-81.

30. Jakicic JM, Winters C, Lagally K, Ho J, Robertson RJ, Wing RR. The accuracy of the TriTrac-R3D accelerometer to estimate energy expenditure. Med Sci Sports Exerc.1999;31(5):747-54.

31. Caspersen CJ, Powell KE, Christenson GM. Physical activity, exercise, and physical fitness: definitions and distinctions for health-related research. Public Health Rep. 1985;100(2):126-31.

32. Torquato E, Gerage A, Meurer S, Borges R, Silva M, Benedetti T. Comparação do nível de atividade física medido por acelerômetro e questionário IPAQ em idosos. Rev. bras. ativ. fís. saúde. 2016;21(2):144-53.

33. Oguma Y, Osawa Y, Takayama M, Abe Y, Tanaka S, Lee IM, et al. Validation of Questionnaire-Assessed Physical Activity in Comparison with Objective Measures Using Accelerometers and Physical Performance Measures Among Community-Dwelling Adults Aged $>/=85$ Years in Tokyo, Japan. J Phys Act Health. 2016:1-28.

34. Chandonnet N, Saey D, Almeras N, Marc I. French Pregnancy Physical Activity Questionnaire compared with an accelerometer cut point to classify physical activity among pregnant obese women. PloS one. 2012;7(6):e38818.

35. Guthold R, Ono T, Strong KL, Chatterji S, Morabia A. Worldwide variability in physical inactivity a 51-country survey. Am J Prev Med. 2008;34(6):486-94.

36. Florindo AA, Hallal PC. Epidemiologia da atividade física. Florindo AA, editor. São Paulo: Atheneu; 2011. 210 p.

37. Monteiro CA, Conde WL, Matsudo SM, Matsudo VR, Bonsenor IM, Lotufo PA. A descriptive epidemiology of leisure-time physical activity in Brazil, 1996-1997. Rev Panam Salud Publica. 2003;14(4):246-54.

38. Siqueira FV, Facchini LA, Piccini RX, Tomasi E, Thume E, Silveira DS, et al. [Physical activity in young adults and the elderly in areas covered by primary health care units in municipalities in the South and Northeast of Brazil]. Cad Saude Publica. 2008;24(1):39-54.

39. Chastin SF, Culhane B, Dall PM. Comparison of self-reported measure of sitting time (IPAQ) with objective measurement (activPAL). Physiol Meas. 2014;35(11):2319-28.

40. Oyeyemi AL, Umar M, Oguche F, Aliyu SU, Oyeyemi AY. Accelerometer-determined physical activity and its comparison with the International Physical Activity Questionnaire in a sample of Nigerian adults. PLoS One. 2014;9(1):e87233.

41. Ottevaere C, Huybrechts I, De Bourdeaudhuij I, Sjostrom M, Ruiz JR, Ortega FB, et al. Comparison of the IPAQ-A and actigraph in relation to VO2max among European adolescents: the HELENA study. J Sci Med Sport. 2011;14(4):317-24.

42. Hagstromer M, Ainsworth BE, Oja P, Sjostrom M. Comparison of a subjective and an objective measure of physical activity in a population sample. J Phys Act Health. 2010;7(4):541-50.

43. Boyle T, Lynch BM, Courneya KS, Vallance JK. Agreement between accelerometer-assessed and self-reported physical activity and sedentary time in colon cancer survivors. Support Care Cancer. 2015;23(4):1121-6.

44. Harris TJ, Owen CG, Victor CR, Adams R, Ekelund U, Cook DG. A comparison of questionnaire, accelerometer, and pedometer: measures in older people. Med Sci Sports Exerc. 2009;41(7):1392-402.

45. Sabia S, Cogranne P, van Hees VT, Bell JA, Elbaz A, Kivimaki M, et al. Physical Activity and Adiposity Markers at Older Ages: Accelerometer Vs Questionnaire Data. J Am Med Dir Assoc. 2015.

\section{Acknowledgements}

The authors would like to thank the Angiocorpore Institute of Cardiovascular Medicine for providing support for clinical assessment and cardiopulmonary exercise tests. We also would like to thank Dr. Philipe Rachas Saccab for supervising a significant number of cardiopulmonary exercise tests.

\section{Funding Resources}

São Paulo Research Foundation (FAPESP), grant no. 2011/07282-6 supported this study.

\section{Corresponding author}

Rodrigo Pereira da Silva

Universidade Metropolitana de Santos, Conselheiro Nébias Avenue, 536, Encruzilhada, Santos, SP. Brasil.

Email: r.pereirads@hotmail.com

Manuscript received on September 26, 2016

Manuscript accepted on March 12, 2017

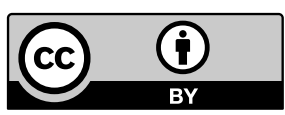

Motriz. The Journal of Physical Education. UNESP. Rio Claro, SP, Brazil - eISSN: 1980-6574 - under a license Creative Commons - Version 3.0 